\title{
NEONATAL EXPANDED SCREENING \\ FOR INHERITED METABOLIC DISEASES: PLANNING BY SIMULATION
}

\author{
Monica Da-Frè, Monica Mazzucato, Cinzia Minichiello, \\ Laura Visonà-Dalla-Pozza \\ Department of Paediatrics \\ University of Padova \\ Via Giustiniani 3, I35128 Padova (Italy) \\ e-mail: epi@pediatria.unipd.it
}

\author{
Giorgio Romanin-Jacur \\ Department of Management and Engineering \\ University of Padova \\ Stradella San Nicola 3, I36100 Vicenza (Italy) \\ e-mail: romjac@dei.unipd.it
}

\section{KEYWORDS}

Metabolic diseases, neonatal screening, simulation model, structure dimensioning.

\begin{abstract}
Inherited metabolic diseases are rare but may cause severe damages if not cared for in time. A neonatal screening program, including a first quick test to all newborns and a second accurate test for patients with positive results, is being planned in Veneto region, northeast Italy. A simulation model describing all operations has been built and implemented with the scope of giving suitable dimension to operating centres, in order to care for all revealed pathology within the maximum time before they may become dangerous for the involved patients. The model is pretty general and its application may be extended to changed situation of the same region or to other regions.
\end{abstract}

\section{INTRODUCTION}

The screening is the application of a test to all subjects of a population with the scope of identifying a disease at the moment when it is asymptomatic. A screening test has not the significance of a diagnostic test: it identifies a person who appears to be sound but probably suffers from a disease among people who do not; people with either positive or suspicious result shall be sent to the doctor for diagnosis and necessary therapy.

The idea of an early disease diagnosis and treatment is simple; conversely the path, which brings on one side to care people for a previously undiagnosed disease and on the other side not to damage those who do not need any treatment, is not simple. Then in (Wilson and Junger 1968) leading criteria were fixed to identify pathologies for which a screening program is appropriate; such criteria were repeatedly updated and are synthetized in (Andermann et al. 2008) as follows:

- the screening program shall meet a recognized need; - screening objectives shall be defined from the beginning;

- target population shall be defined;

- scientific evidence of screening program effectiveness is necessary;
- the plan shall integrate education, evaluation, clinical services and management plans;

- a quality control, which minimizes potential screening risks, is necessary;

- the plan shall assure well informed choices, confidentiality and autonomy respect;

- the plan shall promote screening access and equity to the whole population;

- evaluation plans shall be prepared from the beginning;

- screening total benefits shall outweigh damages.

The scope of neonatal screening lays in identifying newborns with severe pathologies in order to promote appropriate interventions to avoid or to improve adverse outcomes (Wilcken and Wiley 2008).

Biochemical mass test on newborns began in 1960 with the adoption of a screening for phenylketonuria, a rare congenital metabolism error which, if not treated, leads to a severe mental retardation. Gutrie in 1960 developed a methodology to measure phenylalanine concentration in blood; this test required a few blood drops taken from the heel and soaked into a blotting paper now known as Gutrie card (Marsden and Levy 2010); moreover it has the characteristic of being quickly effected on a large sample number. Such a test first became compulsory in Massachusetts in 1963, but soon in many states neonatal screening test plans took place. Note that the same sample may be used for many tests, so that other pathologies were introduced in the neonatal screen plans.

In the 90's the development of tandem mass spectrometry brought a great change to neonatal screening, as this method permits identification of a large number of metabolites from the same sample of a few blood drops on the blotting paper, so that the screening for 30-40 metabolic pathologies is possible. Pilot plans developed in Australia and New England studied tandem mass screening effectiveness and revealed a higher identification capacity if compared with clinical diagnoses (Zytkovicz et al. 2001, Wilcken et al. 2003); moreover results showed the advantage of better prognosis of identified and precociously treated patients.

Neonatal screening programs with tandem mass technology were developed in Australia, Canada, Qatar and in the majority of U.S.A.. In Europe 24 states 
activated such plans, either applied to the whole country or limited to some regions (Bodamer et al. 2007). The set of screened metabolic diseases is different among the various states.

Even if many papers were written about simulation in health care, no paper was found about simulation of neonatal screening except (Da Frè 2011).

\section{PROJECT FOR AN EXPANDED NEONATAL SCREENING IN VENETO REGION}

A project to execute an expanded neonatal screening in Veneto region (northeast Italy), 4,900,000 inhabitants, has been recently initiated. Such a project plans to create a network which includes two already operating centres, placed in Verona (West Veneto) and in Padova (East Veneto); the catchment area includes 42 birth centres, of which 15 in the provinces of Verona and Vicenza, which will refer to Verona, with about 19,000 newborns per year, and 27 in the provinces of Padova, Rovigo, Treviso, Venezia and Belluno, which will refer to Padova, with about 27,000 newborns per year. Probably the catchment area will expand to two neighbour regions in the future.

Pahologies to be screened for are listed below; for each pathology there is written the official name, the usual abbreviation and the priority; high priority pathologies are characterized by +++ , which specifies that such pathologies require beginning the appropriate therapy within the first week of life, middle priority pathologies by ++ , as they require to begin the therapy within the second week of life, low priority by + , as they do not require any therapy within the first two weeks of life:

Phenylketonuria (PKU)

Tyrosinemia, Type I (TYR I)

Citrullinemia (CIT)

Argininosuccinic Aciduria (ASA)

Arginase Deficiency (ARG)

Maple Syrup Urine Disease (MSUD)

Propionic Acidemia (PA)

Methylmalonyl-CoA Mutase (MMA)

Methylmalonic acidemia with homocystinuria type $\mathrm{C} / \mathrm{D}(\mathrm{Cbl} \mathrm{C} / \mathrm{D})$

Isovaleric acidemia (IVA)

Glutaric aciduria 1 (GA I)

Very long chain acyl-CoA dehydrogenase deficiency (VLCAD)

Long chain 3-hydroxyacyl-CoA dehydrogenase deficiency (LCHAD)

Medium chain acyl-CoA dehydrogenase deficiency (MCAD)

Short chain Acyl-CoA dehydrogenase deficiency (SCAD)

Glutaric aciduria 2 (GA II)

Carnitine palmitoyl transferase 1 deficiency (CPT I)

Carnitine palmitoyl transferase II deficiency (CPT II)
Carnitine-acylcarnitine translocase deficiency (CACT)

Carnitine uptake deficiency (CUD)

Glycogen Storage Disease Type II (Pompe

Disease) (GSD II)

Fabry Disease (FD)

Mucopolysaccharidosis I, II, VI (MPS I, II, VI)

Actions related to neonatal screening for metabolic diseases are reported in Figure 1. Within two-three days from birth a sample is taken from every newborn; the sample is quickly dispatched to the first level centre of reference, where it is measured as soon as the machine is idle; if the first measuring gives a borderline result, then a second measuring is performed; if the result is uncertain a new sample is taken immediately, if it is related to a premature newborn a new sample is taken after fifteen days; if the result is clear and positive, the newborn is sent to the second level centre in Padova, to make a further test, in order to get an accurate diagnosis and to set up a therapy plan; the second level test is executed as soon as a free slot is found. Note that first level centres are planned to operate for six days a week.and the only second level centre for five days a week.

\section{THE PROBLEM}

The main concern of Region Health authorities is to find the right dimension for the two first level centres, placed in Verona and Padova, in terms of capacity, i.e., number of measured samples per day, and for the second level centre, placed in Padova, in terms of number of tests executed per week.

It is obvious the capacity shall be decided in order not to impose dangerous delays in the processing of samples and positive patients, but not to require excessive expense by creating overdimensioned centres. Keep in mind that the study shall be open to reconsider centres dimensioning in the case either the population of the catchment area changes, or the catchment area expands. Given the variability of birth process and the flexibility we require to the model, we chose simulation as the most suitable technique to solve the problem; such a methodology permits us to know in advance the effects of our suggestions without implementing any new method in clinical practice; moreover many different alternatives can be tested witout any actual experiment.

\section{DATA ANALYSIS}

Data concerning birth process were obtained from the local birth records reporting births of year 2009. An accurate study revealed that the birth rate depends both on the month of the year and on the day of the week: the expected amount of births per day is given by a regression model expressed by the formula:

$\mu_{\mathrm{ij}}=\alpha+\beta_{\mathrm{i}}+\delta_{\mathrm{j}} \quad$ where $\mathrm{i}=1, \ldots, 12$ and $\mathrm{j}=1, \ldots, 7$ 


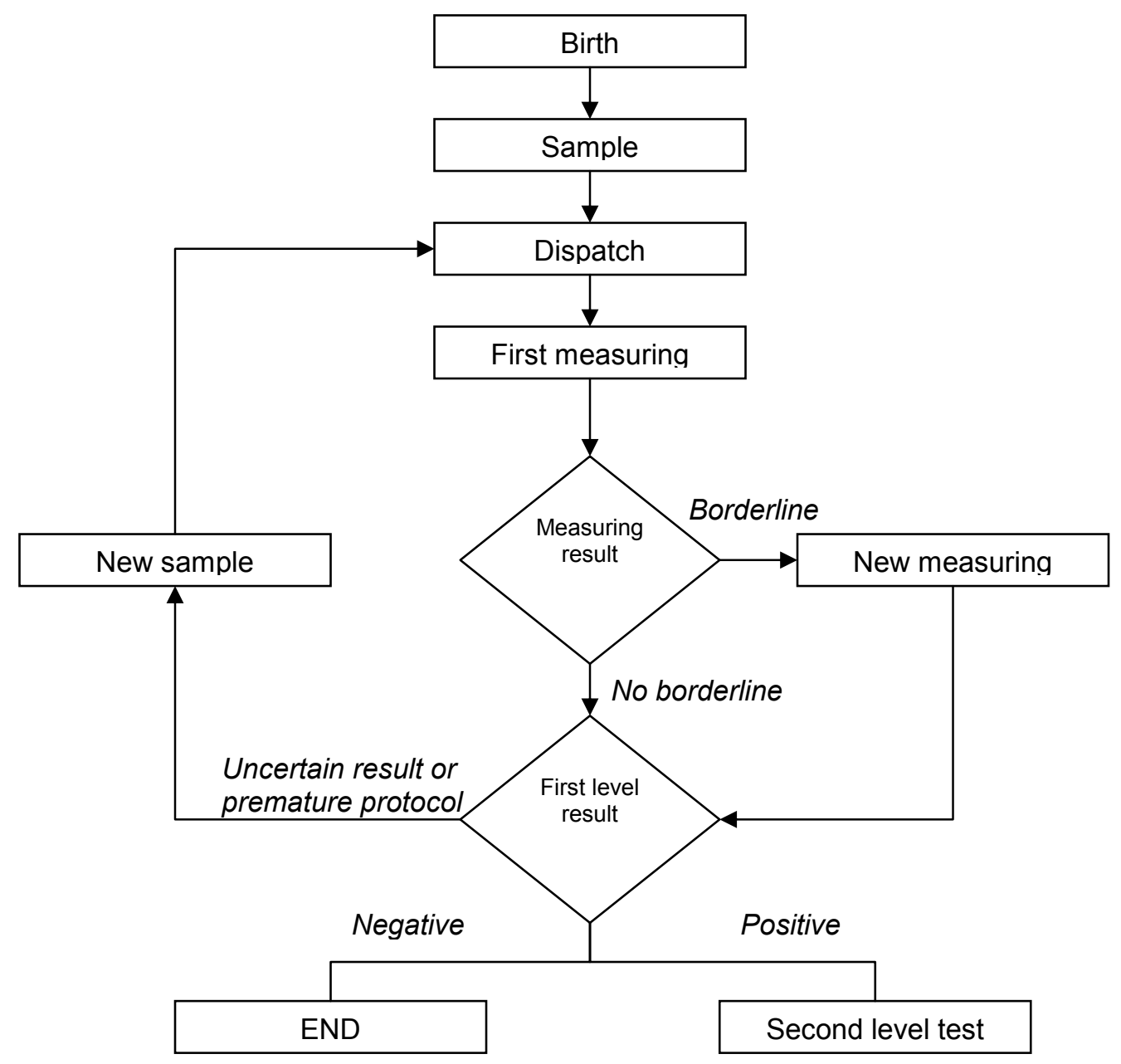

Figure 1: Flow Chart of Actions Related to Screening

according to the following parameters:

\begin{tabular}{rr}
\hline$\alpha$ & 105,48 \\
\hline$\beta_{1}$ & 0,00 \\
\hline$\beta_{2}$ & $-1,57$ \\
\hline$\beta_{3}$ & $-7,78$ \\
\hline$\beta_{4}$ & $-7,39$ \\
\hline$\beta_{5}$ & $-3,90$ \\
\hline$\beta_{6}$ & $-2,32$ \\
\hline$\beta_{7}$ & 7,15 \\
\hline$\beta_{8}$ & 2,86 \\
\hline$\beta_{9}$ & 10,42 \\
\hline
\end{tabular}

The proportions of births referring to the two centres of Verona and Padova are respectively $39 \%$ and $61 \%$.

For what concerns the expected proportions of positive results to sample measurements for the various

pathologies, they are obtained in part from the results of screenings operated in other countries or regions and in part from clinical studies (Da Frè 2011); as the estimated values are strongly different, for every pathology a minimal and a maximal proportion has been considered, as reported below; note that some pathologes are grouped together as their marker is the same; the minimum and maximum proportions have been treated separately.

\begin{tabular}{lll}
\hline PA+MMA+ Cbl C/D & $0,0144 \%$ & $0,0840 \%$ \\
\hline IVA & $0,0156 \%$ & $0,0213 \%$ \\
\hline GA I & $0,0014 \%$ & $0,0248 \%$ \\
\hline PKU & $0,0358 \%$ & $0,0692 \%$ \\
\hline TYR I & $0,0212 \%$ & $0,0256 \%$ \\
\hline MSUD & $0,0074 \%$ & $0,0113 \%$ \\
\hline ARG & $0,0037 \%$ & $0,0057 \%$ \\
\hline ASA+CIT & $0,0072 \%$ & $0,0122 \%$ \\
\hline
\end{tabular}




\begin{tabular}{lcc}
\hline VLCAD & $0,0006 \%$ & $0,0132 \%$ \\
\hline LCHAD & $0,0030 \%$ & $0,0048 \%$ \\
\hline MCAD & $0,0042 \%$ & $0,0283 \%$ \\
\hline SCAD & $0,0156 \%$ & $0,0254 \%$ \\
\hline GA2 & $0,0006 \%$ & $0,0036 \%$ \\
\hline CPT I & $0,0016 \%$ & $0,0016 \%$ \\
\hline CPT II+CACT & $0,0012 \%$ & $0,0192 \%$ \\
\hline CUD & $0,0356 \%$ & $0,0356 \%$ \\
\hline GSD-II & $0,0390 \%$ & $0,0390 \%$ \\
\hline MF & $0,38 \%$ & $0,38 \%$ \\
\hline MPS & $0,0122 \%$ & $0,0250 \%$ \\
\hline
\end{tabular}

Finally the proportion of repeated tests because of borderline measurement result was estimated at $10 \%$ and the proportion of repeated samples at $2 \%$.

\section{THE MODEL}

A simulation discrete event model of the screening process has been built up and implemented in language MicroSaint 3.2, available at Paediatrics Department.

The model implementation graphical representation is reported in Figure 2.

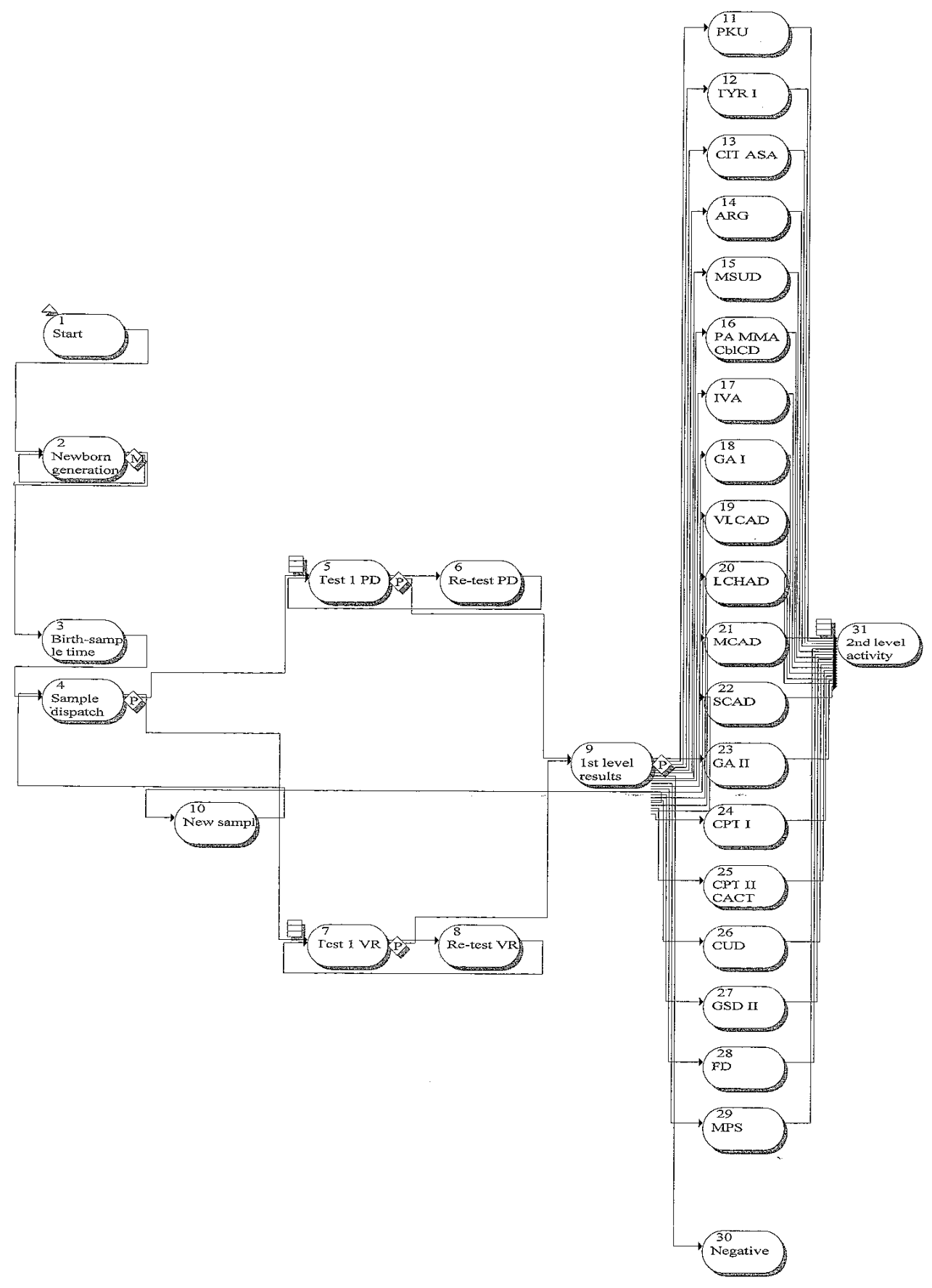

Figure 2: Neonatal Screening Model. 
MicroSaint essential objects are only the following:

- ellipses, called tasks, representing activities, connected with time spending and use of resources; every activity is characterized by its time distribution, its releasing condition, and its beginning and ending effect, which consist in sequential codes;

- $\quad$ striped rectangles, called queues, representing waiting lines, characterized by their queueing rule;

- $\quad$ rhombuses, called decisions, which may be of three types: multiple, when all following activities are performed, tactical, when one of the following activities is performed according to a condition, probabilistic, when one of the following activities is chosen according to given probabilities;

- arrows, representing sequences among activities.

In the model of Figure 2 tasks perform the following functions:

- task 1 initializes simulation and defines all coefficients of birth process;

- task 2 generates newborns in a random independent way;

- $\quad$ task 3 describes time spent between birth and sample (rectangular distribution between 2 and 3 days);

- task 4 describes time spent to dispatch the sample (rectangular distribution between 0.2 and 1 days) and shares samples between the two first level centres;

- tasks 5 and 7 describe the measurement execution in the two centers (which requires 24 hours) and probabilistically select samples to be retested respectively in the two centres; retest operations are described by tasks 6 and 8; capacities of two centres, i.e., maximum number of measurement performed per day, are to be stated according to model results; measurements are performed for six days a week;

- task 9 describes measurement result management: uncertain results and results related to premature newborns are addressed to task 10 which describes the second sample, followed by dispatching and new measurement; positive results are addressed to tasks 11 to 29, each one related to one pathology, according to the given proportions, where the corresponding priority is assigned; negative results are addressed to task 30 and exit the system;

- task 31 describes second level centre activities; patients related to positive results are enqueued according to their pathology priority and get diagnosis and treatment protocol; centre capacity is to be stated according to model results.

The model performed one run of one year after a warmup of one year. The model could be validated by comparing the number of generated newborns.with the actual one, taken from the Region Health Service records.

\section{MODEL RESULTS}

As seen above, model results concern times spent for the two tests, related to the centres capacities.

In a first phase first level centres have been suitably dimensioned. In Table 1 there are reported the mean times between the sample arrival and the test result obtaining, in correspondence of four scenarios, related to four different centres capacities (105 and 65, 115 and 75,125 and 85, 140 and 90 measured samples per day). In the first scenario we observe both centres collapse; in the second scenariothe processing times are improved but the utilization rate is too high; in the third scenario the processing times do not reduce dramatically but the utilization rate is acceptable; in the fourth scenario the utilization rate is too low; therefore, by observing other results too, the chosen dimensioning is 125 and 85, which is considered the best compromise for costs and service quality; a small percentage of samples requires more than 3 days, but that cannot be eliminated because of the Sunday closure of the centre. Note that the percentage of samples requiring more than 3 days is an exact simulation result and not a mean. Other results, as for instance utilization, have confidence intervals which are not essential as the result is used only as a suggestion.

Table 1: First Level Centres Behaviour for Different Capacities.

\begin{tabular}{lcccccccc}
\hline & \multicolumn{3}{c}{ Padova screening centre } & \multicolumn{3}{c}{ Verona screening centre } \\
\hline & $\begin{array}{c}\mathbf{1}^{\circ} \\
\text { sce. }\end{array}$ & $\begin{array}{c}\mathbf{2}^{\circ} \\
\text { sce. }\end{array}$ & $\begin{array}{c}\mathbf{3}^{\circ} \\
\text { sce. }\end{array}$ & $\begin{array}{c}\mathbf{4}^{\circ} \\
\text { sce. }\end{array}$ & $\begin{array}{c}\mathbf{1}^{\circ} \\
\text { sce. }\end{array}$ & $\begin{array}{c}\mathbf{2}^{\circ} \\
\text { sce. }\end{array}$ & $\begin{array}{c}\mathbf{3}^{\circ} \\
\text { sce. }\end{array}$ & $\begin{array}{c}\mathbf{4}^{\circ} \\
\text { sce. }\end{array}$ \\
\hline Centre capacity (meas/day) & 105 & 115 & 125 & 140 & 65 & 75 & 85 & 90 \\
\hline Mean time & & & & & & & & \\
\hline All newborns & 3,7 & 1,6 & 1,5 & 1,4 & 13,2 & 1,6 & 1,5 & 1,4 \\
\hline Newborns without re-test & 3,6 & 1,5 & 1,4 & 1,3 & 13,0 & 1,4 & 1,3 & 1,3 \\
\hline Newborns with re-test & 4,8 & 2,6 & 2,5 & 2,5 & 14,2 & 2,6 & 2,5 & 2,5 \\
\hline Maximum time & 8,2 & 3,4 & 3,1 & 3,1 & 20,0 & 3,2 & 3,1 & 3,1 \\
\hline \% newborns >3 days & 56,3 & 1,8 & 1,7 & 1,4 & 100,0 & 2,0 & 1,5 & 1,7 \\
\hline Centre utilization rate & $99 \%$ & $90 \%$ & $83 \%$ & $73 \%$ & $100 \%$ & $89 \%$ & $78 \%$ & $74 \%$ \\
\hline
\end{tabular}


Once stated the first level centres capacities, the second level centre capacity is obtained on the basis of the waiting times before the second level test for the different priority pathologies. In Table 2 such times are reported related to the minimum and to the maximum proportion of positive first level tests taken from the literature. It may be observed that small capacity variations cause dramatic changes for low priority pathologies; a capacity of 7 is acceptable for minimum positive proportion and a capacity of 10 for the maximum positive proportion. The exact positive proportion will be known after a sufficient operating time.

Table 2: Second Level Centre Behaviour for Different Capacities.

\begin{tabular}{|c|c|c|c|c|c|c|c|}
\hline & \multicolumn{4}{|c|}{$\begin{array}{l}\text { First level MINIMUM } \\
\text { positive rate }\end{array}$} & \multicolumn{3}{|c|}{$\begin{array}{c}\text { First level MAXIMUM } \\
\text { positive rate }\end{array}$} \\
\hline & $1^{\circ}$ sce. & $2^{\circ}$ sce. & $3^{\circ}$ sce. & $4^{\circ}$ sce. & $1^{\circ}$ sce. & $2^{\circ}$ sce. & $3^{\circ} \mathrm{sce}$ \\
\hline Week capacity & 5 & 6 & 7 & 8 & 8 & 10 & 12 \\
\hline \multicolumn{8}{|c|}{ Mean waiting time between birth and second level inspection } \\
\hline Priority +++ & 6,2 & 5,9 & 5,7 & 5,5 & 5,7 & 5,7 & 5,6 \\
\hline Priority ++ & 6,7 & 6,6 & 5,9 & 5,7 & 6,5 & 5,8 & 5,5 \\
\hline Priority + & 78,8 & 28,0 & 8,0 & 6,3 & 17,8 & 6,6 & 5,8 \\
\hline \multicolumn{8}{|c|}{ Maximum waiting time between birth and second level inspection } \\
\hline Priority +++ & 8,4 & 7,9 & 8,2 & 7,5 & 7,7 & 7,7 & 7,5 \\
\hline Priority ++ & 13,5 & 13,4 & 8,7 & 8,2 & 10,2 & 9,4 & 7,8 \\
\hline Priority + & 108,8 & 53,5 & 17,9 & 10,7 & 36,0 & 13,6 & 9,5 \\
\hline \multicolumn{8}{|l|}{$\%$ long times } \\
\hline Priority $+++>7$ days & 21,4 & 14,0 & 6,8 & 7,4 & 10,8 & 8,8 & 1,9 \\
\hline Priority $++>14$ daysi & 1,4 & 0,0 & 0,0 & 0,0 & 0,0 & 0,0 & 0,0 \\
\hline Priority $+>21$ daya & 96,3 & 62,5 & 0,0 & 0,0 & 37,5 & 0,0 & 0,0 \\
\hline Centre utilization rate & $100 \%$ & $100 \%$ & $84 \%$ & $67 \%$ & $100 \%$ & $80 \%$ & $63 \%$ \\
\hline
\end{tabular}

It is evident that the model may be employed successfully in different conditions, related to changes in positive results proportions, changes in the population, changes in the number of operating centres, with small adjustments.

\section{CONCLUSION}

A simulation model describing neonatal screening for metabolic diseases in Veneto region has been built up and implemented to give suitable dimension to operating centres. The model may be easily extended to different situations either in the same region or in other regions.

\section{REFERENCES}

Andermann A, Blancquaert I, Beauchamp S, Déry V. 2008. "Revisiting Wilson and Jungner in the genomic age: a review of screening criteria over the past 40 years." Bull World Health Organ 86(4) (Apr): 317-9.

Bodamer OA, Hoffmann GF, Lindner M. 2007. "Expanded newborn screening in Europe." $J$ Inherit Metab Dis. 30(4) (Aug): 439-44.

Da Frè M. 2011. "Progettazione dello screening neonatale allargato per le malattie metaboliche ereditarie: impatto nella popolazione e nei servizi sanitari del Veneto." PhD Thesis, Department of Paediatrics, University of Padova (Italy).

Marsden D, Levy H. 2010. "Newborn screening of lysosomal storage disorders." Clin Chem. 56(7) (Jul): 1071-9.
Wilcken B, Wiley V, Hammond J, Carpenter K. 2003. "Screening newborns for inborn errors of metabolism by tandem mass spectrometry." $N$ Engl $J$ Med. 348(23) (Jun): 2304-12.

Wilcken B, Wiley V. 2008. "Newborn screening." Pathology 40(2) (Feb): 104-15.

Wilson JM, Jungner G. 1968. "Principles and practice of screening for disease." World Health Organization .

Zytkovicz TH, Fitzgerald EF, Marsden D, Larson CA, Shih VE, Johnson DM, Strauss AW, Comeau AM, Eaton RB, Grady GF 2001. "Tandem mass spectrometric analysis for amino, organic, and fatty acid disorders in newborn dried blood spots: a twoyear summary from the New England Newborn Screening Program." Clin Chem. 47(11) (Nov): 1945-55.

MONICA DA-FRE' was graduated in Statistics at the University of Padova, obtained a Master in Biostatistics and Epidemiological Methodology at the University of Pavia and is currently student of the $\mathrm{PhD}$ school in Developmental Medicine and Planning Sciences at the University of Padova. She is now working as a researcher at the Epidemiology Unit of the Regional Health Agency of Tuscany.

MONICA MAZZUCATO was born in Padova, Italy. She received her MD at the University of Padova (2000) and she obtained her board certification in Community Medicine (2004) and her $\mathrm{PhD}$ in Developmental Sciences and Epidemiology (2008) at the University of Padova. She works at the Veneto Register of Rare 
Diseases, Epidemiology and Community Medicine Unit, Paediatrics Department, University of Padova. She also teaches Epidemiology and Public Health at the Faculty of Medicine, University of Padova.

CINZIA MINICHIELLO was born in Montebelluna (Treviso), Italy. She graduated in Pharmaceutical Chemistry at the University of Padova (2006) and she obtained her $\mathrm{PhD}$ in Developmental Sciences and Epidemiology at the University of Padova (2010). She works as a pharmacist at the Veneto Register of Rare Diseases, Epidemiology and Community Medicine Unit, Paediatrics Department, University of Padova.

LAURA VISONA'-DALLA-POZZA was born in Valdagno (Vicenza), Italy. She graduated in Statistics at the University of Padova (2000) and she obtained her $\mathrm{PhD}$ in Developmental Sciences and Epidemiology at the University of Padova (2005). She works as a statistician at the Veneto Register of Rare Diseases,
Epidemiology and Community Medicine Unit, Paediatrics Department, University of Padova. She is also teaching Medical Statistics at the Faculty of Medicine, University of Padua.

GIORGIO ROMANIN-JACUR was born in Padova, Italy, and went to the University of Padova, where he studied Electronical Engineering and obtained his degree in 1970 . He worked for ten years for the National Council of Researches before moving in 1980 to the University of Padova where he is now teaching Operations Research and OR Application to the students of the class of Management Engineering and developing researches about Operations Research applications in the fields of industry, transportation and health services. 